\title{
Dados sintáticos do português brasileiro em gramáticas brasileiras oitocentistas
}

\author{
Bruna Soares Polachini \\ Universidade de São Paulo (USP), São Paulo, São Paulo, Brasil \\ bpolachini@gmail.com \\ Stela Maris Detregiacchi Gabriel Danna \\ Universidade de São Paulo (USP), São Paulo, São Paulo, Brasil \\ smdanna@ hotmail.com
}

DOI: $\underline{\text { http://dx.doi.org/10.21165/el.v45i1.800 }}$

\begin{abstract}
Resumo
No início do século XIX, emerge uma gramaticografia brasileira do português, mas é apenas no final do século que dados sintáticos típicos de um português falado no Brasil ganham relevância nessas obras. No mesmo período, ocorre uma ruptura teórico-metodológica em benefício de uma corrente que prezava particularidades e comparação entre línguas. Esta nova orientação rompia com uma abordagem filosófica de estudo das línguas. Neste trabalho, procuramos observar as obras já analisadas por Coelho, Danna e Polachini (2014) por outro ângulo. Nosso objetivo é realizar um detalhado estudo dos dados linguísticos selecionados pelos gramáticos no tratamento que deram à sintaxe em suas obras, e verificar se a presença de PB, já observada no estudo mencionado, relaciona-se com uma mudança mais geral na seleção de dados das obras.
\end{abstract}

Palavras-chave: historiografia linguística; gramáticas brasileiras do português; português brasileiro; sintaxe.

Syntactic Data of Brazilian Portuguese in Brazilian Grammar Books from the 1800s

\begin{abstract}
In the early 1800s, there was a study on the Brazilian Portuguese grammar, but it was only at the end of the century that typical syntactic data of the language spoken in Brazil acquired significance in these studies. On the same occasion, there was a theoretical-methodological disruption that gave rise to a stream that valued the particularities and comparisons among languages. This new orientation disrupted the philosophical approach on language studies. Thus, this paperseeks to observe the studies already analyzed by Coelho, Danna and Polachini (2014) on a different perspective. Its goal is to elaborate a detailed study about the linguistic data selected by grammarians when handling syntax in their grammar books, and to examine if the presence of Brazilian Portuguese, already observed in the above-mentioned study, is related to a more generic change in the selection of data for these books.
\end{abstract}

Keywords: linguistic historiography; brazilian portuguese grammar; brazilian portuguese; syntax.

\section{Introdução}

Como sabemos, na primeira década do século XIX, emerge uma gramaticografia brasileira do português (cf. NASCENTES, 1939; ELIA, 1975, CAVALIERE, 2001). É também nesse século que passa a haver interesse na distinção entre a língua portuguesa falada no Brasil e a língua portuguesa falada em Portugal. Pinto (1978) ressalta publicações que, ao longo do século XIX, dissertaram sobre essa distinção, algumas com 
viés romântico e nacionalista, outras com interesse científico, próprio dos estudos sobre a linguagem da época. Coelho $(2003,2008)$ e Vidal Neto (2010), por exemplo, estudam lexicógrafos e um gramático que tiveram essa preocupação. Coelho, Danna e Polachini (2014) fizeram uma varredura em nove gramáticas oitocentistas e em um conjunto de artigos já novecentistas de Said Ali, a fim de observar menções ao português brasileiro (doravante PB) nas obras. No artigo, as autoras dividiram os fenômenos que os gramáticos referenciavam como próprios de um português brasileiro em quatro categorias: fonéticos, morfológicos, lexicais, sintáticos e gerais ${ }^{1}$, como vemos na tabela adiante (cf. COELHO; DANNA; POLACHINI, 2014, p.121-122).

Tabela 1. Quantificação e distribuição de dados do PB presentes em textos gramaticais brasileiros do século XIX

\begin{tabular}{c|c|c|c|c|c|c}
\hline FENÔMENOS & Fonéticos & Morfológicos & Lexicais & Sintáticos & Gerais & TOTAL \\
\cline { 1 - 5 } OBRAS & 0 & 0 & 0 & 1 & 0 & 1 \\
\hline Morais Silva (1806) & 0 & 0 & 0 & 0 & 0 & 0 \\
\hline $\begin{array}{c}\text { Coruja (1835) } \\
\text { Sotero dos Reis } \\
\text { (1866) }\end{array}$ & 0 & 0 & 0 & 0 & 0 & 0 \\
\hline $\begin{array}{c}\text { Carneiro Ribeiro } \\
(1877)\end{array}$ & 3 & 0 & 4 & 2 & 0 & 9 \\
\hline Ribeiro (1881) & 4 & 1 & 0 & 13 & 0 & 18 \\
\hline $\begin{array}{c}\text { Pacheco e Lameira } \\
(1887)\end{array}$ & 3 & 3 & 6 & 3 & 3 & 18 \\
\hline Ribeiro (1889[1887]) & 1 & 0 & 3 & 1 & 2 & 7 \\
\hline $\begin{array}{c}\text { Carneiro Ribeiro } \\
(1890)\end{array}$ & 3 & 0 & 4 & 2 & 0 & 9 \\
\hline Maciel (1902[1894]) & 2 & 2 & 4 & 5 & 0 & 13 \\
\hline $\begin{array}{c}\text { Said Ali } \\
(1919[1908])\end{array}$ & 1 & 0 & 0 & 1 & 1 & 3 \\
\hline
\end{tabular}

Como podemos observar na Tabela1, os dados sintáticos revelaram-se em maior número e, por hipótese, poderiam constituir um material potencialmente interessante de análise, visto que, de acordo com alguns estudos, a gramaticografia brasileira do português passaria por uma ruptura teórica e metodológica no final do século XIX (cf. NASCENTES, 1939; ELIA, 1975; CAVALIERE, 2001; POLACHINI, 2013). É de conhecimento geral que até o último quartel desse século, as gramáticas brasileiras se aproximavam da tradição da grammaire générale francesa. Assim, ainda que o objeto de análise fosse uma língua particular (o português, no caso) este estudo se dava por meio da pressuposição de que, sendo a língua expressão do pensamento, ela estava ancorada em princípios gerais para todas as línguas. No final do século, a gramática brasileira passou a ser influenciada por estudos que prezavam a língua manifestada, procurando compará-la com outras línguas ou estágios mais antigos da própria língua, a fim de descobrir sua procedência genética. Destarte, a ruptura ocorrida provocou uma inversão de interesse, visto que o foco dessa última corrente era a língua manifestada e suas particularidades, em vez de sua adaptabilidade a um modelo geral. Esta mudança teóricometodológica poderia ser parte das justificativas do aumento de fenômenos ditos como próprios de um português falado no Brasil nessas obras (cf. VIDAL NETO, 2010; POLACHINI, 2013).

Neste trabalho, procuramos, portanto, observar as obras já analisadas por Coelho, Danna e Polachini (2014) por outro ângulo. Primeiramente, selecionamos apenas o

\footnotetext{
${ }^{1} \mathrm{Na}$ categoria fenômenos gerais, as autoras do trabalho buscaram reunir aqueles fatos linguísticos que não foram especificados por meio de dados nem, tampouco, pelo nível de articulação.
} 
tratamento da sintaxe das obras. Em segundo lugar, nosso objetivo nesse trabalho foi ver os tipos de dados/exemplos ${ }^{2}$ selecionados para o tratamento da sintaxe em geral, não apenas no que diz respeito aos dados referidos como PB. Portanto, procuramos fazer um detalhado estudo dos dados linguísticos selecionados pelos gramáticos para o tratamento da sintaxe nas gramáticas supracitadas e verificar se a presença tardia de PB neste tratamento, já observada no estudo anterior, relaciona-se com uma mudança mais geral na seleção de dados das obras.

\section{Metodologia}

Como mencionamos acima, nossa análise tem os mesmos materiais do trabalho de Coelho, Danna e Polachini (2014). Entretanto, selecionamos analisar apenas as seções ou artigos destas obras que se referiam ao tratamento da sintaxe. No quadro adiante, explicitamos os materiais e seções analisadas.

Quadro 1. Textos e seções analisadas

\begin{tabular}{|c|c|}
\hline GRAMÁTICA & SEÇÃO ANALISADA \\
\hline $\begin{array}{c}\text { Morais Silva (1806) } \\
\text { Epitome da GrammaticaPortugueza }\end{array}$ & Syntaxe \\
\hline $\begin{array}{c}\text { Coruja (1835) } \\
\text { Compendio da grammatica da lingua nacional dedicado á } \\
\text { mocidade rio-grandense }\end{array}$ & Syntaxe \\
\hline $\begin{array}{c}\text { Sotero dos Reis (1866) } \\
\text { Grammatica portuguesa accommodada aos princípios geraes } \\
\text { da palavra, seguidos de imediata applicação pratica }\end{array}$ & Syntaxe \\
\hline $\begin{array}{c}\text { Carneiro Ribeiro (1877) } \\
\text { Gramática portuguesa philosophica }\end{array}$ & Phraseologia \\
\hline $\begin{array}{c}\text { Ribeiro (1881) } \\
\text { Grammatica Portugueza }\end{array}$ & Syntaxe \\
\hline $\begin{array}{c}\text { Pacheco e Lameira (1887) } \\
\text { Grammatica da Lingua Portugueza para uso dos gymnasios, } \\
\text { lyceus e escolas normaes }\end{array}$ & Lições $29-46^{3}$ \\
\hline $\begin{array}{c}\text { Ribeiro (1889[1887]) } \\
\text { Grammatica portugueza: } 3^{\circ} \text { anno }\end{array}$ & Lições XXIX-XLVI \\
\hline $\begin{array}{c}\text { Carneiro Ribeiro (1890) } \\
\text { Serões Gramaticais ou Nova Grammatica Portugueza }\end{array}$ & Phraseologia \\
\hline $\begin{array}{c}\text { Maciel (1902[1894]) } \\
\text { Grammatica Descriptiva baseada nas doutrinas modernas }\end{array}$ & Syntaxologia \\
\hline $\begin{array}{c}\text { Said Ali (1919[1908, 1895]) } \\
\text { Difficuldades da Língua Portugueza }\end{array}$ & $\begin{array}{l}\text { Collocação dos pronomes pessoaes } \\
\text { regidos de infinitivo ou gerúndio } \\
\text { [p.29-48], Collocação dos } \\
\text { pronomes pessoaes regidos de } \\
\text { formas verbaes finitas [p.49-84], O } \\
\text { infinitivo pessoal [p.85-120], } \\
\text { Verbos sem sujeito [p.121-139] }\end{array}$ \\
\hline
\end{tabular}

Optamos por analisar somente os dados linguísticos baseando-nos na proposta de Swiggers (2004), de que no conteúdo linguístico pode-se distinguir quatro dimensões ou

\footnotetext{
${ }^{2}$ Neste artigo, estamos considerando dados (linguísticos) e exemplos como sinônimos.

3 Os capítulos chamam-se "lições" porque dizem respeito ao Programa de Estudos para os Exames de Língua Portuguesa redigido por Fausto Barreto para o Colégio Pedro II, em 1887. Nele, havia 46 pontos das diversas matérias gramaticais, os quais foram seguidos à risca na dis tribuição do conteúdo de algumas gramáticas, como as de Pacheco e Lameira (1887) e Ribeiro (1889) (cf. RIBEIRO, 2007).
} 
capas: a capa teórica, que é correspondente à visão global da linguagem e concepção das tarefas e do estatuto dos estudos linguísticos; a capa técnica, relativa a técnicas de análise e métodos de apresentação dos dados; a capa documental, definida por Swiggers como a documentação linguística e filológica (número de línguas, tipos de fontes de dados, por exemplo) sobre o qual se baseia o estudo linguístico; e a capa contextual, que diz respeito aos aspectos contextuais e institucionais que podem ter impacto sobre a produção linguística estudada. A proposta tem como um de seus objetivos tornar rupturas mais relativas. Assim, num momento de transição, algumas capas poderiam ser modificadas enquanto outras não. Reforçamos que nosso objetivo, neste trabalho, porém, não é o de compreender essa mudança por completo, mas apenas entender o funcionamento da capa documental nas gramáticas selecionadas.

Polachini (2013) demonstra que a capa documental pode ser um importante indício de mudança técnica e teórica, pois, muito embora haja capas específicas para essas outras duas dimensões do conhecimento linguístico, em alguns casos as mudanças acontecem conjuntamente. Algumas gramáticas, por exemplo, podem apresentar dados de língua manifestada, relacionando-os com dados de língua mental; outras podem apresentar dados de fontes literárias ou relacionadas a um determinado grupo social. Há, ainda, aquelas que enfatizam que a língua de séculos atrás não é a mesma daquela que é contemporânea ao gramático. Esses diferentes modos de referir e selecionar seu objeto de estudo podem ser índices, por exemplo, de que a gramática preconiza a língua enquanto expressão de processos mentais, enquanto uso, enquanto organismo em mutação, ou ainda enquanto uma linguagem sobretudo literária.

A autora estudou justamente o tratamento da sintaxe em algumas das obras que foram, posteriormente, também analisadas por Coelho, Danna e Polachini (2014). A partir dos dados linguísticos encontrados nas seções de tratamento da sintaxe das gramáticas, Polachini (2013) distinguiu cinco categorias, as quais utilizaremos de forma similar, mas adaptada, neste trabalho de mapeamento dos dados das gramáticas. Incluímos ainda uma sexta categoria, relativa a dados de um português de períodos anteriores. No trabalho de Polachini (2013), as gramáticas analisadas não apresentavam esse tipo de dados. Por sua vez, no artigo de Coelho, Danna e Polachini (2014) não se estava buscando por esse tipo de dado, mas apenas por informações do PB. Neste artigo, entretanto, como procuramos observar um viés teórico e técnico por meio da capa documental, importa-nos ver, também, até que ponto os gramáticos se atentaram a apresentar e assumir dados do português como de outros períodos que não o contemporâneo deles.

Assim, neste trabalho, os dados linguísticos levantados em cada obra foram categorizados da seguinte forma: (1) Referência literária explícita, e, neste caso, de que literatura, isto é, se é portuguesa ou brasileira e também de que séculos são essas literaturas, exceto nos casos em que a referência literária era mero documento histórico, o que enquadra o dado na categoria (5); (2) Fala cotidiana (como é o caso das citações que autores fazem, como regional do Brasil, do Brasil como um todo, Portugal, ou mesmo, das colônias); (3) A denominada língua lógico-elíptica que, diferente das duas anteriores, não tem uma referência explícita. São exemplos em que o autor ou corrige ou modifica uma sentença por meio da expressão "isto é". Em geral, as correções são feitas com base na inclusão de um elemento que estava antes implícito (ou elíptico) ou de uma paráfrase da proposição (cuja estrutura era em geral fixa: sujeito-cópula-atributo) em que uma parte anteriormente elíptica é explicitada (ex.: [O mundo] há homens). (4) Língua distinta do português descrito pela obra, como o latim, bastante frequente, ou mesmo o francês, inglês, e outras línguas; (5) Português de períodos anteriores, em que o autor assume que aquele exemplo é referente a um português não contemporâneo ao seu, sendo 
que muitas vezes esses dados vêm atrelados a uma referência literária explícita entretanto, tendo em conta que estas eram mais documentos representativos da língua do que referência para o uso, colocamos esse tipo de dado nesta categoria e não na categoria (1); (6) Genérica, em que tratamos de dados que não se encaixam em nenhuma das quatro categorias anteriores. Neste último caso, o critério é a ausência de referência.

\section{Análise}

É notável que algumas obras recheiem suas páginas de exemplos, ao passo que outras preocupem-se mais com explicações teóricas. Por conta disso, iniciamos a análise proposta observando o número de exemplos apresentados nas obras e o número de páginas destinado ao tratamento da sintaxe delas. Este levantamento resultou em dados numéricos que apresentamos na Tabela 2.

Tabela 2: Quantidade de exemplos por obra.

\begin{tabular}{c|c|c|c}
\hline & Exemplos & Páginas & Ex./Pág. \\
\hline Morais Silva (1806) & 600 & 39 & 7 \\
\hline Coruja (1873[1835]) & 155 & 21 & 5 \\
\hline Sotero dos Reis (1866) & 513 & 103 & 9 \\
\hline Carneiro Ribeiro (1877) & 702 & 78 & 15 \\
\hline Ribeiro (1881) & 1382 & 93 & 8 \\
\hline Pacheco \& Lameira (1887) & 990 & 118 & 9 \\
\hline Ribeiro (1889) & 909 & 103 & 12 \\
\hline Carneiro Ribeiro (1890) & 1546 & 130 & 10 \\
\hline Maciel (1902[1894]) & 1036 & 108 & 5 \\
\hline Said Ali (1919[1908]) & 554 & 110 &
\end{tabular}

A Tabela 2 apresenta, em sua primeira coluna, as obras analisadas nesta pesquisa. Em seguida, encontra-se o número total de exemplos presentes na obra e, ao lado, a quantidade de páginas que cada obra contém. Por fim, a última coluna expõe o resultado da divisão entre a quantidade de exemplos e a de páginas de cada material, possibilitando nos visualizar uma média de exemplos por página.

Vemos que há textos com mais exemplos, enquanto outros não utilizaram tanto este recurso. Em outras palavras, notamos que nem todas as obras dão o mesmo espaço para exemplos. Segundo esta tabela, Coruja (1873[1835]) e Said Ali (1919[1908]), portanto, não recorriam tanto aos exemplos, se comparados com Morais Silva (1806) e Ribeiro (1881).

A escolha por apresentar mais ou menos exemplos nas obras revela-se, neste conjunto de textos, mais uma estratégia pessoal de cada autor, do que uma exigência ligada a uma vinculação teórico-metodoló gica dos autores. Tanto os estudiosos que mais utilizaram exemplos, quanto os que menos utilizaram, pertencem a orientações teóricometodológicas diferentes, isto é, autores vinculados a uma abordagem filosófica da língua, como Morais Silva (1806) e Coruja (1873[1835]) não seguem uma única tendência: o primeiro insere mais que o dobro de dados que o segundo em seu texto gramatical. O mesmo fato ocorre entre Maciel (1902[1894]) e Said Ali (1919[1908]) ${ }^{4}$, que já adotavam um tratamento vinculado a uma perspectiva histórico-comparativa dos estudos linguísticos.

\footnotetext{
4 Para mais informações sobre o tratamento linguístico realizado por Said Ali nestes textos, conferir a dissertação de mestrado de Danna (2014).
} 
Os exemplos da Tabela 2 foram classificados nas seis categorias descritas na seção 2, Metodologia. Reunimos, agora na Tabela 3, a quantidade de exemplos a que chegamos, após categorizá-los.

Tabela3: Quantidade de exemplos (e suas porcentagens) por categoria.

\begin{tabular}{|c|c|c|c|c|c|c|}
\hline & $\begin{array}{l}\text { Referência } \\
\text { Literária }\end{array}$ & $\begin{array}{c}\text { Fala } \\
\text { Cotidiana }\end{array}$ & $\begin{array}{l}\text { Língua } \\
\text { Lógico- } \\
\text { Elíptica }\end{array}$ & $\begin{array}{c}\text { Línguas } \\
\text { Diversas }\end{array}$ & $\begin{array}{c}\text { Português } \\
\text { de períodos } \\
\text { anteriores }^{5}\end{array}$ & $\begin{array}{l}\text { Língua } \\
\text { Genérica }\end{array}$ \\
\hline $\begin{array}{c}\text { Morais Silva } \\
(1806)\end{array}$ & $\begin{array}{c}160 \\
(26,7 \%)\end{array}$ & $\begin{array}{c}2 \\
(0,3 \%)\end{array}$ & $\begin{array}{c}45 \\
(7,5 \%)\end{array}$ & $\begin{array}{c}5 \\
(0,8 \%)\end{array}$ & - & $\begin{array}{c}388 \\
(64,7 \%)\end{array}$ \\
\hline $\begin{array}{c}\text { Coruja } \\
(1873[1835])\end{array}$ & - & - & $\begin{array}{c}14 \\
(9 \%)\end{array}$ & - & - & $\begin{array}{c}141 \\
(91 \%)\end{array}$ \\
\hline $\begin{array}{l}\text { Sotero dos } \\
\text { Reis (1866) }\end{array}$ & $\begin{array}{c}3 \\
(0,6 \%) \\
\end{array}$ & - & $\begin{array}{c}51 \\
(9,8 \%) \\
\end{array}$ & $\begin{array}{c}5 \\
(0,9 \%) \\
\end{array}$ & - & $\begin{array}{c}454 \\
(88,7 \%)\end{array}$ \\
\hline $\begin{array}{c}\text { Carneiro } \\
\text { Ribeiro (1877) }\end{array}$ & $\begin{array}{c}173 \\
(24,6 \%)\end{array}$ & $\begin{array}{c}3 \\
(0,4 \%)\end{array}$ & $\begin{array}{c}9 \\
(1,3 \%)\end{array}$ & $\begin{array}{c}26 \\
(3,7 \%)\end{array}$ & - & $\begin{array}{c}491 \\
(70 \%)\end{array}$ \\
\hline Ribeiro (1881) & $\begin{array}{c}37 \\
(2,7 \%) \\
\end{array}$ & $\begin{array}{c}16 \\
(1,2 \%) \\
\end{array}$ & $\begin{array}{c}10 \\
(0,7 \%) \\
\end{array}$ & $\begin{array}{c}52 \\
(3,8 \%) \\
\end{array}$ & $\begin{array}{c}15 \\
(1,0 \%) \\
\end{array}$ & $\begin{array}{c}1252 \\
(90,6 \%)\end{array}$ \\
\hline $\begin{array}{c}\text { Pacheco \& } \\
\text { Lameira } \\
(1887) \\
\end{array}$ & $\begin{array}{c}202 \\
(20,4 \%)\end{array}$ & $\begin{array}{c}21 \\
(2,1 \%)\end{array}$ & $\begin{array}{c}4 \\
(0,4 \%)\end{array}$ & $\begin{array}{c}121 \\
(12,2 \%)\end{array}$ & $\begin{array}{c}82 \\
(8,3 \%)\end{array}$ & $\begin{array}{c}560 \\
(56,6 \%)\end{array}$ \\
\hline Ribeiro (1889) & $\begin{array}{c}47 \\
(5,1 \%) \\
\end{array}$ & $\begin{array}{c}15 \\
(1,7 \%) \\
\end{array}$ & - & $\begin{array}{c}35 \\
(3,9 \%)\end{array}$ & $\begin{array}{c}62 \\
(6,8 \%) \\
\end{array}$ & $\begin{array}{c}750 \\
(82,5 \%) \\
\end{array}$ \\
\hline $\begin{array}{c}\text { Carneiro } \\
\text { Ribeiro (1890) }\end{array}$ & $\begin{array}{c}366 \\
(23,7 \%) \\
\end{array}$ & $\begin{array}{c}38 \\
(2,5 \%) \\
\end{array}$ & $\begin{array}{c}25 \\
(1,5 \%) \\
\end{array}$ & $\begin{array}{c}65 \\
(4,2 \%) \\
\end{array}$ & $\begin{array}{c}24 \\
(1,6 \%) \\
\end{array}$ & $\begin{array}{c}1028 \\
(66,5 \%)\end{array}$ \\
\hline $\begin{array}{c}\text { Maciel } \\
(1902[1894])\end{array}$ & $\begin{array}{c}651 \\
(62,8 \%) \\
\end{array}$ & $\begin{array}{c}18 \\
(1,8 \%)\end{array}$ & - & - & - & $\begin{array}{c}367 \\
(35,4 \%) \\
\end{array}$ \\
\hline $\begin{array}{c}\text { Said Ali } \\
(1919[1908])\end{array}$ & $\begin{array}{c}343 \\
(61,9 \%)\end{array}$ & $\begin{array}{c}9 \\
(1,6 \%)\end{array}$ & $\begin{array}{c}18 \\
(3,2 \%)\end{array}$ & $\begin{array}{c}20 \\
(3,6 \%)\end{array}$ & $\begin{array}{c}17 \\
(3,2 \%)\end{array}$ & $\begin{array}{c}147 \\
(26,5 \%)\end{array}$ \\
\hline
\end{tabular}

Na Tabela 3, listamos inicialmente as obras. Nas demais colunas que se seguem, estão os resultados quantitativos representados em números absolutos e porcentuais. Assim, como exemplificação, em Morais Silva (1806), encontramos 160 exemplos de referência literária, o que corresponde a $26,7 \%$ de todos os exemplos levantados nesta obra. Encontramos apenas 2 de fala cotidiana, 45 de língua idealizada, 5 de línguas diversas do português, nenhum dado de português de períodos anteriores e 388 de exemplos de língua genérica (sem referência).

A análise global dos dados da Tabela 3, considerando tanto os números absolutos, quanto os percentuais, revela que Morais Silva (1806), Maciel (1902) e Said Ali (1919[1908]) apresentam muitos exemplos com referência literária, isto é, provenientes de obras da literatura lusófona. Ressaltamos, no entanto, que os autores usam a referência literária de forma diversa. Em Maciel (1902[1894]) e Said Ali (1919[1908]), há exemplos literários de obras publicadas em séculos diversos (desde o século XVI até o XIX). Dados provenientes de textos de Luís de Camões (1524-1580), Alexandre Herculano (18101877) e Gonçalves Dias (1823-1864) estão presentes nestas exemplificações. Lembrandonos que Dias é brasileiro, é importante observar que nestas obras do final do século XIX e início do século XX, os dados literários brasileiros ganham espaço. Já Morais Silva (1806) apresenta apenas autores portugueses e dos séculos XVI e XVII, como Fernão Mendes Pinto (1524-1583) e o próprio Camões.

\footnotetext{
5 Desses, tinham referência literária: Ribeiro (1881) 9; Pacheco e Lameira (1887) 61; Ribeiro (1889) 35; Carneiro Ribeiro (1890) 11; Said Ali (1919[1908]) 3.
} 
Em relação a este critério, colocamo-nos um questionamento sobre as categorias estabelecidas. Por exemplo, ao analisar as Noções de grammatica portuguesa (1887), de Pacheco e Lameira, e a Grammatica Portugueza (1889), de João Ribeiro, vimos que os gramáticos apresentam dados de Luís de Camões, Fernão Lopes (1380/90-1460) e de Antônio Vieira (1608-1697) como documentos de um português mais antigo, que hoje é desusado, os quais se enquadrariam na categoria (5), de português de períodos anteriores. Seria possível, dessa maneira, usar a literatura não apenas para justificar um uso canônico, mas também como registro de um uso mais antigo, que deixou de existir. Outras gramáticas apresentam esse recurso, como enfatizamos na nota de rodapé número 5 .

Nos dados de referência literária, Maciel (1902[1894]) não trata de mudanças da língua portuguesa que poderiam ter sido registradas por meio de exemplos de obras distintas e distantes no tempo. Já nos textos de Júlio Ribeiro (1881), Pacheco e Lameira (1887), João Ribeiro (1889) e Said Ali (1919[1908]), os exemplos evidenciariam tanto permanências como mudanças de um determinado uso ao longo dos anos. Por outro lado, Morais Silva (1806) e também Carneiro Ribeiro (1890), eventualmente, citam fragmentos da literatura para comprovar que o uso da língua portuguesa estaria equivocado até mesmo entre o grupo dos usuários considerados "cultos"6.

Os nossos melhores escritores, todavia, nem sempre observarambem esta regra, variando o vocábulo meio em casos em que como adverbio devia ele ficar invariavel; o que se vê nos seguintes exemplos: 'Iam cançados da briga e meios mortos de medo' [...]. (CARNEIRO RIBEIRO, 1890, p.257)

Com relação aos exemplos de fala cotidiana, observamos que esta categoria de dados ganha mais espaço nas obras gramaticais ao longo do século, ainda que não seja o tipo de exemplo mais usado pelos autores. Embora a porcentagem seja pouco expressiva, os exemplos de fala cotidiana proporcionam ao leitor das gramáticas conhecer alguns aspectos dos falares informais de portugueses e brasileiros: "Duas frases se conhecem em Portugal em que o pronome atono occupa indubitavelmente o primeiro lugar do discurso: t'arrenego e me melem se. Fazem parte do falar do povo." (SAID ALI, 1919[1908], p.78). Ademais, a apresentação desse tipo de exemplo pode ser relacionada ao interesse maior por dados manifestados e particularidades linguísticas, o qual se torna cada vez maior com a influência de métodos provenientes de uma orientação histórico-comparativa.

Ao contrário do que vimos com os exemplos da fala cotidiana, os dados de língua lógico-elíptica tornam-se cada vez menos frequentes no final do século XIX, na medida em que esse tipo de dado perde relevância juntamente com a queda do modelo da grammaire générale francesa, que, como já comentamos anteriormente, preconizava a descrição linguística por meio da relação desta com procedimentos gerais do pensamento. A reformulação de períodos e a explicitação da estrutura abstrata de uma frase (por meio de expressões como "isto é", "quer dizer", entre outros) são estratégias recorrentes neste tipo de exemplificação, como verificamos nos fragmentos a seguir.

Quando veis? i. édize me o tempo, quando veis. (MORAES SILVA, 1806, p. 84)

\footnotetext{
${ }^{6}$ Ressaltamos que Carneiro Ribeiro (1877, p. 393, 396-397) já apresentava, em alguns poucos momentos, dados retirados de textos de séculos anteriores, como de Fernão Lopes e de João de Barros, dizendo que seguiam uma regra, mas que "hoje" a maior parte dos gramáticos apres entariam outra regra. Diferentemente das outras gramáticas, não assume, entretanto, que aqueles dados seriam "desusados” ou referentes a um "português antigo", portanto, não o colocamos na categoria (5), de português de períodos anteriores.
} 
(03) Fui á capital do orbe christão que ha muito desejava visitar; isto é, porque ha muito $a$ desejava visitar (SOTERO DOS REIS, 1866, p. 212)

(04) <<Pedro ama $>><<$ ama $>$ decompõe-se em <<é amante〉> (RIBEIRO, 1881, p. 194)

A Tabela 3 ainda nos mostra que os exemplos de línguas diversas - ou seja, de línguas diferentes do português- não tinha praticamente espaço nas gramáticas do início do século XIX. Contudo, este tipo de dado ganha importância ao longo do século, de modo semelhante ao que acontece com os exemplos de fala cotidiana. A diferença, entretanto, é que, proporcionalmente, os exemplos de línguas diversas cresceram mais do que os exemplos de fala cotidiana, o que pode ser um indício da preocupação destes autores, que buscariam fazer uma análise comparativa entre o português e demais línguas ou com estágios anteriores do português.

O portuguez*), ao contrario do castelhano e do italiano, tem como regra não principiar o discurso pelo pronome atono. Dizemos: Praz-me saber, Coutou- lhe que... ao passo que entre os hespanhoes são correntes frases como Le mandó que viniese, Me gusta, e entre os italianos Mi dispiace, Mi favedere." (SAID ALI, 1919[1908], p. 29-30)

Assim, como vemos no fragmento acima, a maioria dos exemplos de língua estrangeira é de línguas latina ou neolatinas. No entanto, é possível encontrar exemplos do alemão e até de dialetos escandinavos em Pacheco e Lameira (1887) e Said Ali (1919[1908]): "Este caso particular observa-se nas orações existenciaes ha homens, il y a des maisons, il est des hommes, ou no alemão es gibt Menschen (literalmente: elle dá homens)." (SAID ALI, 1919[1908], p. 134).

Os exemplos de português de períodos anteriores aparecem apenas no final do século, período em que o impacto das técnicas da gramática histórico-comparativa emergia e se tornava, paulatinamente, mais intenso. Esses dados dão ao leitor uma dimensão histórica da língua, como se ela estivesse em constante mudança, a qual poderia ser documentada, muitas vezes, por meio de textos do passado, como mostram os dados frequentemente referenciados. Os autores que usam desse recurso com mais frequência são Pacheco e Lameira (1887) e Ribeiro (1889).

O PARTICIPIO PASSADO, no portuguez antigo, sempre que vinha construido com o verbo ter (e ser) e - ainda no Sec. XVI -, concordava com o sujeito do verbo em genero e numero: -- bom servidor e leal nos serviços que lhe tinha feitos (F. Lopes). E do Jordão a areia tinha vista (Cam.); votos que tinha feitos; quantas culpas tinham commetidas (F. Mendes), etc. (PACHECO; LAMEIRA, 1887, p. 465-466)

Finalmente, observamos que os dados de língua genérica (sem referência) são a grande maioria em quase todos os gramáticos, exceto por Maciel (1902) e Said Ali (1919[1908]). A diminuição de exemplos sem referência nestas duas últimas obras de reflexão gramatical selecionadas parece mostrar que, no final do século XIX e início do século XX, o fazer gramatical tenderia a estar embasado em análise de dados observáveis e registrados em textos literários.

\section{Resultados}

A análise realizada permitiu a verificação de algumas tendências, presenças e ausências nos tipos de dados identificados nas obras selecionadas. Em maior detalhe, 
referimo-nos: a) à escassez de exemplos de língua lógico-elíptica nas obras após meados do século XIX; b) à preferência, pelos gramáticos, por inserir em suas obras tanto exemplos de língua genérica (sem referência), quanto exemplos com referência literária de obras renomadas da cultura luso-brasileira; c) ao aumento do número de exemplos de fala cotidiana e de línguas diversas nas obras ao longo do século XIX; d) ao surgime nto e aumento da presença de exemplos de português de outros períodos nas últimas duas décadas do século.

Os exemplos sintáticos, portanto, dão indícios de que os autores, ao longo do século XIX, metodologicamente: i) excluíram dados elípticos ou lógicos, não observáveis, relacionados a uma orientação filosófico-especulativa, como a grammaire générale; ii) priorizaram a análise de dados observáveis, muitos deles presentes em obras consideradas clássicas da literatura luso-brasileira ou mesmo de fala cotidiana, referindose ao uso; e iii) passaram a aproximar fenômenos do português a de outras línguas e também ao português antigo. Estes indícios parecem alinhar-se, portanto, a uma metodologia própria dos estudos histórico-comparativos.

Considerando-se, portanto, que os resultados do trabalho de Coelho, Danna e Polachini (2014) demonstram que as gramáticas começam a apresentar números significativos de fenômenos sintáticos especificados como um português falado no Brasil nas duas últimas décadas do século XIX, e que nesse mesmo momento vemos um paulatino aumento da análise de línguas diversas, da fala cotidiana, e, em alguns casos, de referência literária, pode-se relacionar o aumento de dados sintáticos de PB com uma mudança no tipo de dado selecionado pelos autores. Eles parecem, minimamente, trocar aqueles dados que apresentavam uma língua lógica-subjacente por outros diversos tipos, supracitados, que ratificam a análise da língua manifestada. Mais especificamente, é possível também fazer uma relação direta entre o aumento de fala cotidiana e o aumento de dados do $\mathrm{PB}$, já que este tipo de dado estaria dentro do conjunto daquele. É interessante, no entanto, mostrar que esses dados, de fala cotidiana, não emergem sozinhos, mas junto com outros tipos de dados, incluindo o português de outros períodos, que, parece-nos, tinham como base a priorização de particularidades de dados manifestados (e, eventualmente, registrados) da língua portuguesa.

\section{Considerações finais}

De modo geral, a presente pesquisa comprovou a importância do estudo da capa documental referente às obras gramaticais selecionadas, revelando que esta dimensão pode fornecer dados relevantes sobre as estratégias e métodos de cada autor em seu fazer gramatical. Além disso, ela pode também indicar tendências, já que observamos a queda de alguns tipos de dados e o aumento de outros em períodos específicos, dependendo da orientação teórico-metodológica a que se vinculava a obra. 


\section{REFEFÊNCIAS}

CARNEIRO RIBEIRO, E. Gramática portuguesa philosophica. Bahia: Catilina, 1877. $447 \mathrm{p}$.

Serões Gramaticais. Bahia: Livraria Catilina, 1890. 369 p.

CAVALIERE, R. S. Uma proposta de periodização dos estudos linguísticos no Brasil. Alfa, São Paulo, 45, p. 49-69, 2001.

COELHO, O. F. A anguzada lexicográfica luso-bundo-americana: língua e identidade nacional na segunda metade do século XIX. 2003. 215 f. Tese (Doutorado em Linguística) - Faculdade de Filosofia, Letras e Ciências Humanas, Universidade de São Paulo, São Paulo.

Os nomes da língua: configuração e desdobramento do debate sobre a língua brasileira no século XIX. Revista do IEB. São Paulo, n. 47, p. 140-160, set. 2008.

COELHO, O; DANNA, S.; POLACHINI, B. O português do Brasil em gramáticas brasileiras do século XIX. Revista Confluência. Instituto de Língua Portuguesa do Liceu Literário Português, v.46, n.43, 2013. Disponível em <http//llp.bibliopolis.info/confluencia/pdf/3322.pdf>. Acesso em: 3 out. 2015.

CORUJA, A. Alvares Pereira. Compendio da grammatica da lingua nacional dedicado á mocidade rio-grandense. Porto Alegre: Typographia de V. F. de Andrade, 1835. 68 p.

DANNA, S. M. D. G. Metalinguagem e 'escolha de retórica' em Bello (1853[1847]) e Said Ali (1919[1908]): faces dos estudos gramaticais na América do Sul. 2014. $218 \mathrm{f}$. Dissertação (Mestrado em Letras) - Faculdade de Filosofia, Letras e Ciências Humanas, Universidade de São Paulo, São Paulo.

ELIA, S. E. Ensaios de filologia e linguística. Rio de Janeiro: Grifo; Brasília: INL, 1975. $334 \mathrm{p}$.

MACIEL, M. de A. Grammatica descriptiva baseada nas doutrinas modernas. 3a edição augmentada com muitas notas e resumos synopticos. Rio de Janeiro e Paris: H. Garnier Livreiro-Editor, 1902[1894]. 360 p.

MORAIS SILVA, A. de. Epítome da Grammatica Portugueza. Lisboa: Simão Thaddeo Ferreira, 1806. 163 p.

NASCENTES, A. Estudos filológicos ( $1^{a}$ série). Rio de Janeiro: Civilização Brasile ira, 1939.

PACHECO DA SILVA JÚNIOR, M.; LAMEIRA DE ANDRADE. Grammatica da Lingua Portugueza para uso dos gymnasios, lyceus e escolas normaes. Rio de Janeiro: J. G. de Azevedo, 1887. 537 p.

PINTO, E. P. O Português do Brasil: textos críticos e teóricos, 1 -1820/1920, fontes para teoria e a história. São Paulo: Edusp, 1978. 510 p.

POLACHINI, B. S. O tratamento da sintaxe em gramáticas brasileiras no século XIX: estudo historiográfico. 2013. 219 f. Dissertação (Mestrado em Letras) -Faculdade de Filosofia, Letras e Ciências Humanas, Universidade de São Paulo, São Paulo.

RIBEIRO, J. C. Grammatica Portugueza. São Paulo: Typographia de Jorge Seckler, 1881. $299 \mathrm{p}$.

Grammatica portugueza: $3^{\circ}$ anno. 3. ed. Rio de Janeiro: Livraria Clássica de Alves \& C.,1889[1887]. 326 p. 
"A Procellaria: 17 de Abril de 1887". In: Cartas Sertanejas; Procellarias (Edição Fac-símile). São Paulo: Imprensa Oficial do Estado de São Paulo: FUNDAP, 2007. p. 85-94.

SAID ALI, M. Difficuldades da Língua Portugueza. Rio de Janeiro: Livraria Acadêmica, 1919[1908; 2. ed. - revista pelo autor]. 327 p.

SOTERO DOS REIS, F. Grammatica portugueza accommodada aos principios geraes da palavra, seguidos de immediata applicação pratica. Maranhão: Typ. de R. de Almeida, 1866. 274 p.

SWIGGERS, P. "Modelos, Métodos y Problemas en la historiografía de la linguística". Nuevas Aportaciones a la historiografía lingüística. Actas del IV Congresso Internacional de la SEHL. La Laguna (Tenerife), 22 al 25 de octubre de 2003, p. 113-146, 2004.

VIDAL NETO, J. B. A Grammatica portugueza, de Júlio Ribeiro: um corte epistemológico na gramaticografia brasileira e a questão da língua portuguesa no Brasil. 2010. 141 f. Dissertação (Mestrado em Letras) - Faculdade de Filosofia, Letras e Ciências Humanas, Universidade de São Paulo, São Paulo.

Recebido em: 05/10/2015

Aprovado em: 01/03/2016 